\title{
Thermal and Structural Analyses of Semi-metallic Gasket Joined with Graphite Seal for Ship Engine Piping Flange
}

\author{
Jeong-seok Oh*, In-sup Lee ${ }^{* *}$, Han-ki Yoon ${ }^{* * *}$ and Heung-kyoung Sung ${ }^{*+k+k}$ \\ "Advanced Nuclear Materials Technology Institute, Dong-Eui University, Busan, Korea \\ "Department of Materials Engineering, Dong-Eui University, Busan, Korea \\ ${ }^{* * *}$ SUNG CHANG Co., LTD., E Korea Institute of Science and Technology Information, Busan, Korea \\ SUNG CHANG Co., LTD., Busan, Korea \\ 선박엔진 배관 플랜지용 세미금속 가스켓의 열전달 및 구조해석 \\ 오정석 ${ }^{*}$ 이인섭** $\cdot$ 윤한기 ${ }^{* * *}$ - 성흥경 \\ "동의대학교 차세대원자력소재기술연구소 \\ *동의대학교 신소재공학과 \\ *주식회사 성창 기업부설연구소, 한국과학기술정보연구원 \\ 주식회사 성창 기업부설연구소
}

KEY WORDS: Semi-metallic gasket 세미금속 가스켓, Seal 실, Expanded graphite 팽창흑연, Finite element analysis 유한요소해석, Stainless steel 스테인리스 강

\begin{abstract}
We performed thermal and structural analyses to evaluate the structural integrity of a semi-metal gasket for a flange with increases in the internal fluid temperature and pressure using a commercial FEA program. As a thermal analysis result, the temperature distribution of the gasket body increased with an increase in the internal fluid temperature until the maximum fluid temperature of $600{ }^{\circ} \mathrm{C}$. In addition, the structural analysis showed that contact pressures of more than $35 \mathrm{MPa}$ occurred uniformly in the graphite seal regions. It was found that no fluid leakage occurred under the load conditions for the structural analysis because the contact pressure in the graphite seal region was greater than the maximum internal fluid pressure of $35 \mathrm{MPa}$. Therefore, we demonstrated the structural integrity of the semi-metal gasket by performing the thermal and structure analyses under the maximum fluid temperature of $600{ }^{\circ} \mathrm{C}$ and the internal fluid pressure of $35 \mathrm{MPa}$.
\end{abstract}

\section{1. 서 론}

실 재료(Seal material)는 구조물, 기계부품, 각종 기기 등 유체 의 누설(Leakage) 방지용으로 사용되는 밀봉재이며, 고온, 고압, 부식, 유해성 유체 등 가혹한 조건 아래에서 완벽한 성능을 요 구한다. 실은 소형의 부품이지만 기능 및 역할은 대단히 중요하 다. 실이 장착된 부위에 고온·고압 증기, 화학약품 등 누설이 발생되었을 때 작업자의 안전에 미치는 영향은 치명적이다 (Lee et al., 2013).

가스켓은 선박 엔진, 압력용기 등 배관 플랜지 고정 접합면에 가스켓을 삽입하고 볼트 등으로 체결하여 누설을 방지하는 정 적 실(Static seal)을 말한다. 가스켓 종류는 일반적으로 금속 가
스켓, 비금속 가스켓, 또한 금속재료와 비금속재료를 조합하여 사용하는 세미금속 가스켓(Semi-metal gasket)이 있으며, 비금속 재료가 가지고 있는 유연성, 탄력성과 금속 재료가 가지고 있는 강도, 내열성 등 이점을 조합함으로써 광범위한 온도 및 압력 조건에서 뛰어난 기밀성을 발휘할 수 있는 특징이 있다. 기존의 널리 사용되고 있는 대표적인 세미금속 가스켓은 스파이럴 와 운드 가스켓(Spiral Wound Gasket)이 있다.

본 연구에서는 기존의 고온·고압 환경에서 우수한 기밀성능 을 발휘하는 스파이럴 와운드 가스켓 보다 경제성, 성능면에서 보다 유리한 세미금속 가스켓을 개발하였으며, 금속 바디부와 흑연 실로 결합된 새로운 형상의 혁신적인 가스켓이다. Fig. 1(a) 는 기존의 스파이럴 와운드 가스켓, Fig. 1(b)는 세미금속 가스

Received 28 March 2017, revised 18 September 2017, accepted 19 October 2017

Corresponding author In-Sup Lee: +82-51-890-2287, islee@deu.ac.kr

It is noted that this paper is revised edition based on proceedings of KIM 2016 Gyeongju.

(c) 2017, The Korean Society of Ocean Engineers

This is an open access article distributed under the terms of the creative commons attribution non-commercial license (http://creativecommons.org/licenses/by-nc/3.0) which permits unrestricted non-commercial use, distribution, and reproduction in any medium, provided the original work is properly cited. 


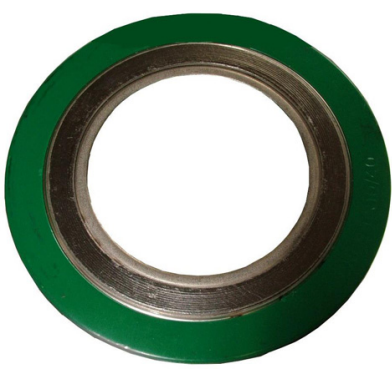

(a) Spiral wound gasket

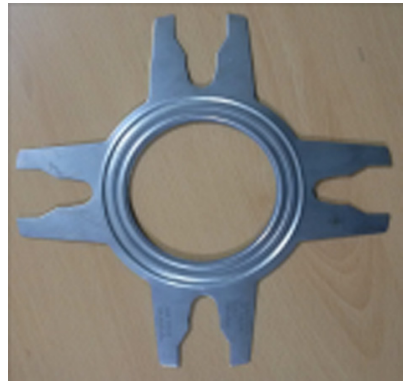

(b) Semi-metal gasket
Fig. 1 Gasket geometry

켓을 나타내고 있다. 날개 모양의 바디부와 바디 원형부 요철에 흑연실 각 2 개씩 바디 앞면과 뒷면에 부착한다. 특히 독특한 디 자인의 날개 모양 형상은 가스켓 체결 시 배관 플랜지의 외경 크기가 다양하게 변화하여도 동일한 크기의 가스켓으로 볼트를 체결할 수 있도록 설계하였다. 또한 작업자가 가스켓 체결시 날 개부분을 손으로 잡고 간단히 가스켓을 체결할 수 있도록 작업 용이성을 고려하여 설계하였다. 바디 부는 SUS316 재질이며 요 철부에 부착되는 실은 천연 흑연 성분을 $98 \%$ 포함한 유연한 성 질을 가지고 있는 팽창 흑연이다. 세미 금속가스켓은 기존의 스 파이럴 와운드 가스켓에 있는 용접부 및 기계가공 공정을 없애 고 간단한 프레스 성형만으로 단시간에 제조가 가능하며, 단가 면에서 경제적이고 성능이 우수하다. 가스켓 바디 두께도 기존 의 $3.2 \mathrm{~mm}$ 에서 $1.6 \mathrm{~mm}$ 로 얇지만 뛰어난 기밀성과 내구성을 가지 고 있다. 또한 유연성과 복원력이 크고 내화학성, 고열전도율을 가진 팽창 흑연 실을 금속 가스켓 바디 요철부에 삽입시켜 고 온 및 고압에서 기밀성을 극대화할 수 있도록 하였다. 본 연구 의 세미금속 가스켓은 선박 엔진, $\mathrm{LNG} \cdot \mathrm{LPG}$ 선, 석유·해양플 랜트 등의 고온, 고압 배관 플랜지 등에 적용하여 기존의 스파 이럴 와운드 가스켓을 대체할 것이다.

세미금속 가스켓의 구조 건조성을 확인하기 위하여 상용 유 한요소 해석 프로그램 Ansys workbench 13.0을 이용하여 고온 $\left(600^{\circ} \mathrm{C}\right)$ 및 최대압력 $(35 \mathrm{MPa})$ 을 가지는 유체의 누설여부를 열전 달 및 구조해석을 통하여 실링부의 접촉 면압을 해석하여 평가 하였다. 특히 플랜지 내부 유체(물) 온도 및 압력 변화에 따른 가스켓의 누설 유무를 평가하였다(Krishna et al., 2007; Haruyama et al., 2013).

\section{2. 실험방법}

\section{1 흑연시트의 인장시험}

유연한 흑연 시트의 인장시험은 KS M ISO 1924-2를 참고하

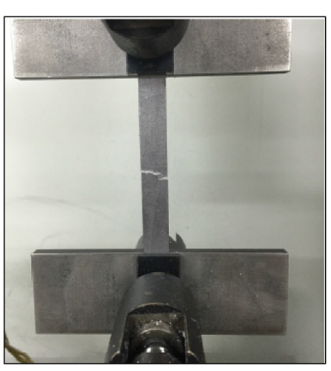

(a) Apparatus of tensile test

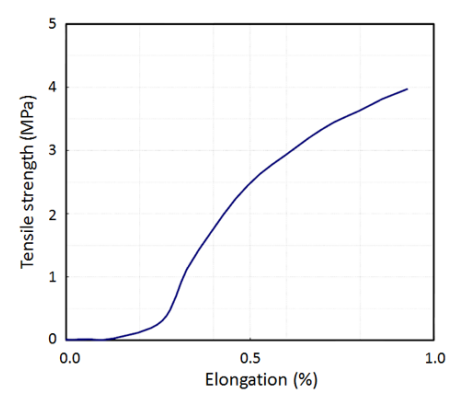

(b) Tensile test graph
Fig. 2 Tensile test of expanded graphite sheet

여 실시하였다. 흑연시크 크기 $210 \times 15 \mathrm{~mm}, 10$ 개를 준비하여 인 장시험을 실시하였다. Fig. 2는 유연한 흑연 시트의 인장시험 모 습 및 인장시험 결과 그래프를 나타내었다. 인장시험에서 얻은 재료 물성치는 열전달 해석 및 구조해석의 재료 물성치로 이용 하였다.

\section{2 세미금속 가스켓의 유한요소 해석}

세미금속 가스켓의 누설 여부를 평가하기 위하여 열전달해석 과 구조해석을 수행하였다. Fig. 3은 유한요소 해석에 사용된 배관 플랜지용 세미가스켓의 3D CAD 모델이며, 해석 모델은 플랜지, 금속가스켓, 흑연 실, 볼트, 너트로 구성되어 있다. Table 1은 유한요소해석을 위한 플랜지용 세미금속 가스켓의 각 부위별 재료의 상온 물성치를 나타내었다(Mathan and Prasad, 2012). 가스켓 바디 재질은 스테인리스강 SUS304, 두께는 $1.6 \mathrm{~mm}$, 실은 팽창흑연, 볼트, 너트는 $\mathrm{S} 35 \mathrm{C}$ 이다. Fig. 4는 각 재 료의 고온환경에서의 물성치로서 열전달 및 구조해석의 물성치 로 적용하였다(Afanasov et al., 2009). Fig. 5(a)는 플랜지, 가스 켓, 흑연실의 유한요소 3차원 모델을 나타내었으며, Fig. 5(b)는 유한요소 해석 과정을 단순화하기 위하여 $3 \mathrm{D} \mathrm{CAD}$ 모델의 $1 / 8$ 모델을 나타내었다. 유한요소 $1 / 8$ 모델의 메시 형상을 Fig. 6에 나타내었다.

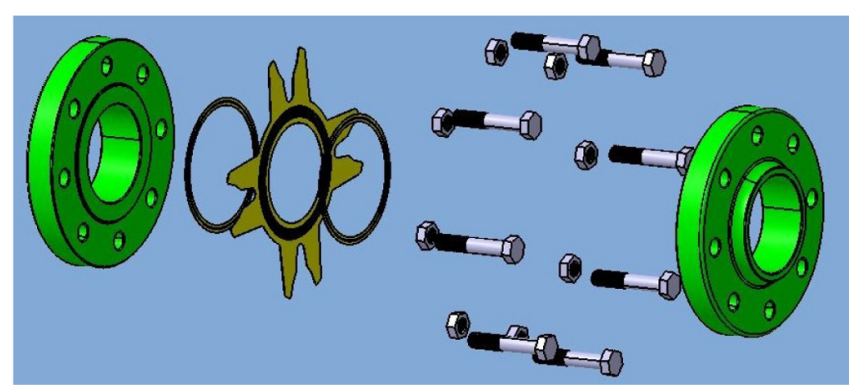

Fig. 3 3D CAD model of flange and gasket

Table 1 Material properties for FEA

\begin{tabular}{cccccc}
\hline \hline Part & Material & Young's modulus [GPa] & Yield strength [MPa] & Tensile strength [MPa] & Poisson's ratio \\
Gasket & SUS304 & 193 & 205 & 520 & 0.3 \\
Seal & Graphite & 1.16 & 2.59 & 3.98 & 0.2 \\
Flange & SUS316 & 214 & 290 & 580 & 0.3 \\
Bolt \& Nut & S35C & 210 & 500 & 800 & 0.3 \\
\hline
\end{tabular}




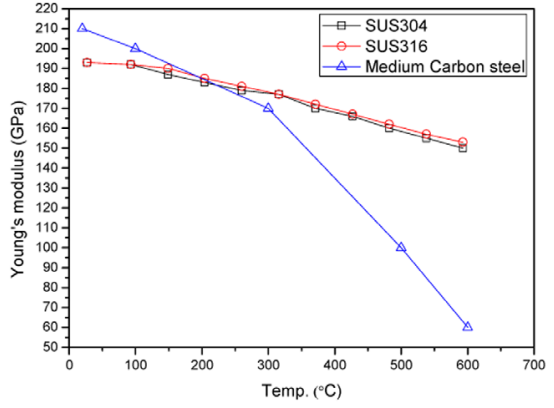

(a) Young's modulus

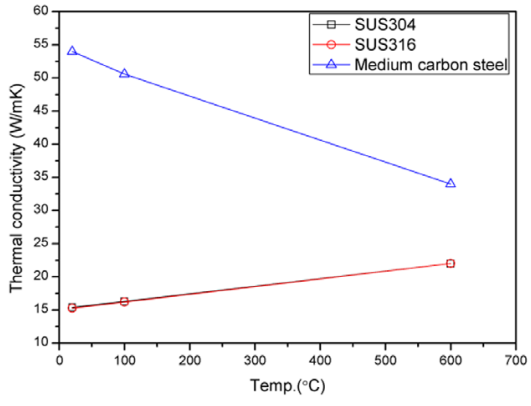

(b) Thermal conductivity

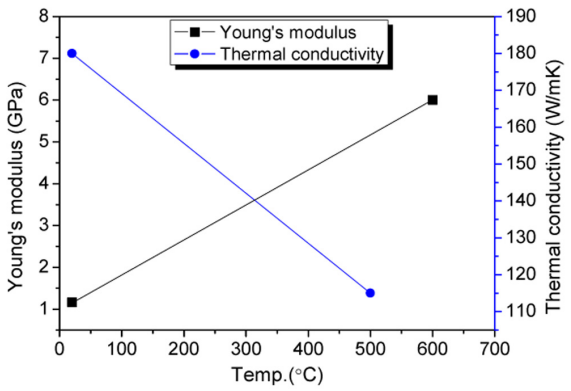

(c) Material properties of graphite

Fig. 4 Materials properties at high temperature
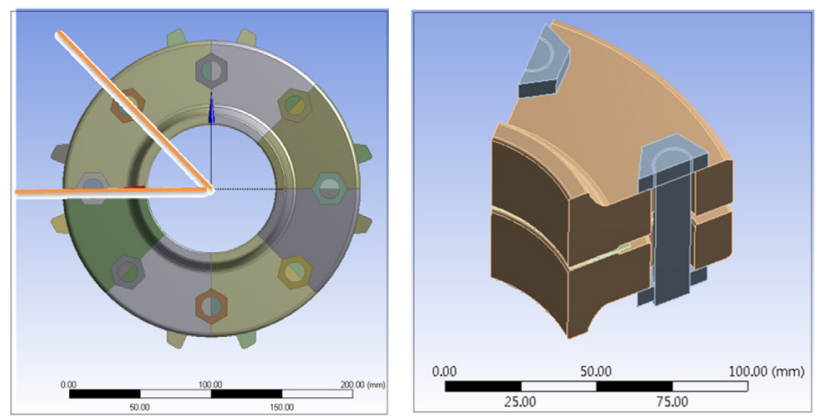

(a) 3D model of flange and gasket (b) 1/8 model of flange and gasket

Fig. 5 Finite element model of flange gasket

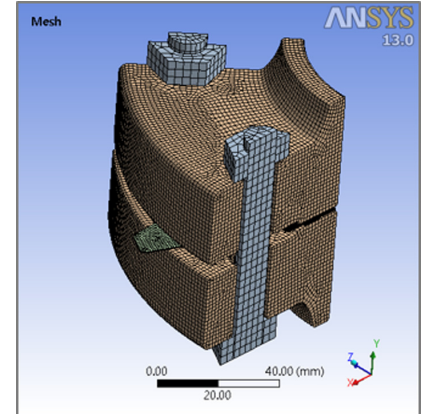

(a) $1 / 8$ model of flange and gasket

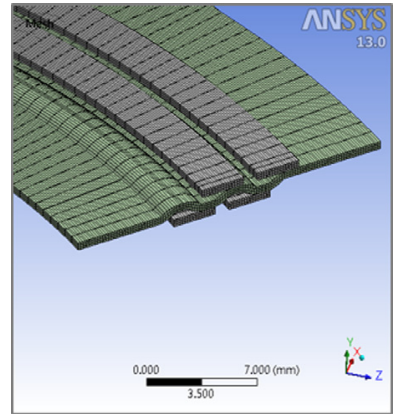

(b) Gasket and graphite seal
Fig. 6 Finite element mesh of flange gasket

\section{3. 열전달 및 구조해석 결과}

\section{1 가스켓의 열전달 해석}

열전달 해석 경계조건을 Fig. 7에 나타내었다. 플랜지 외부 표면은 공기와 접촉하는 부분으로 온도 $22^{\circ} \mathrm{C}$, 자연 대류열전달 계수 $5.0 \times 10^{-6}\left[\mathrm{~W} / \mathrm{mm}^{2} \cdot{ }^{\circ} \mathrm{C}\right]$ 을 적용하였다(Fig. 7(a)). 플랜지 내부 벽면은 유체(물)가 접촉하는 부분으로 대류열전달계수 $1.2 \times 10^{-3}\left[\mathrm{~W} / \mathrm{mm}^{2}\right.$ - ${ }^{\circ} \mathrm{C}$ ], 내부 유체 온도는 $22^{\circ} \mathrm{C}, 600^{\circ} \mathrm{C}$ 로 적용하였다(Fig. 7(b)).

플랜지 내부 유체온도 $22^{\circ} \mathrm{C}$ 및 $600^{\circ} \mathrm{C}$ 에서 가스켓 바디의 열 전달 해석 결과와 온도 분포 등고선을 Fig. 8 에 나타내었다. 플 랜지 내부 유체온도 $600^{\circ} \mathrm{C}$ 의 경우 가스켓 바디의 최대온도 $599.74^{\circ} \mathrm{C}$, 최저온도 $256.39^{\circ} \mathrm{C}$ 를 나타내었다(Fig. $8(\mathrm{C})$ 참조). Fig. $8(\mathrm{~d})$ 는 플랜지 내부 유체 온도변화에 따른 열전달해석 결과를 그래프로 나타내었다. 플랜지 내부 유체온도가 증가할수록 가
스켓 바디의 최대온도 및 최소대온도도 증가하였으며, 또한 최 대온도 및 최저온도의 격차는 더욱 크게 나타났다.

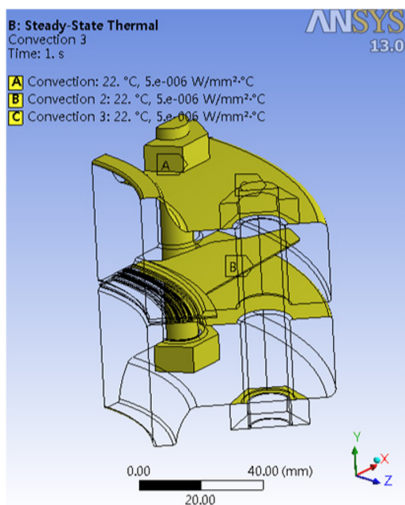

(a) Outer surface

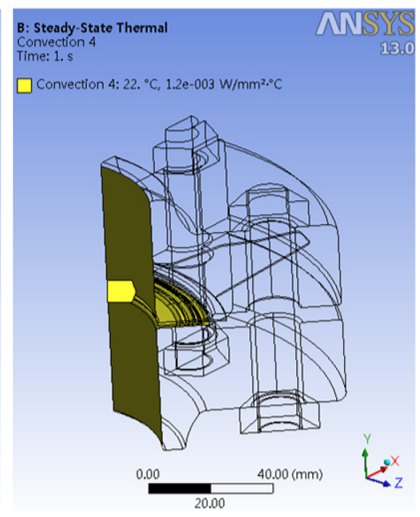

(b) Inner surface
Fig. 7 Boundary conditions for thermal analysis in flange gasket

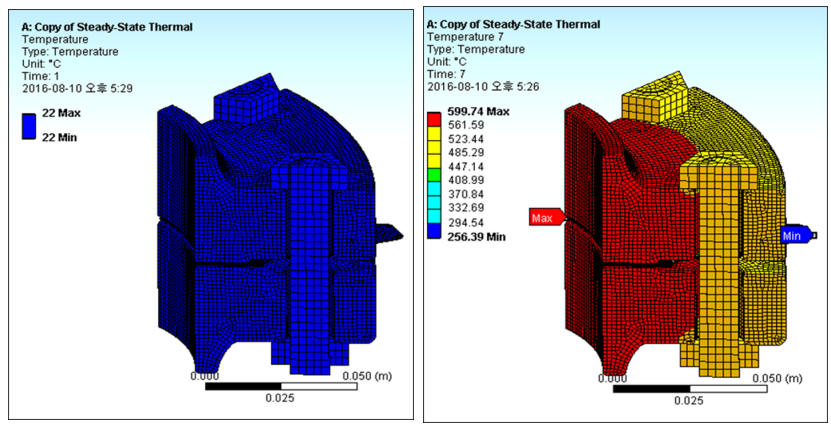

(a) Internal fluid temp. of $22^{\circ} \mathrm{C}$

(b) Internal fluid temp. of $600^{\circ} \mathrm{C}$
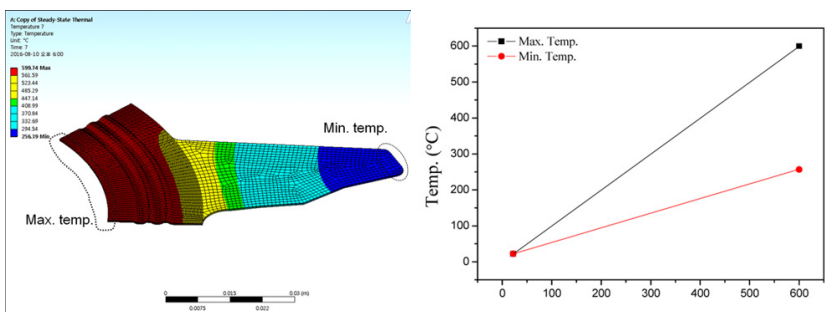

(c) Temperature distribution in (d) Thermal analysis result in gasket Gasket body at internal fluid temp. of $600^{\circ} \mathrm{C}$ body

Fig. 8 Temperature distributions on the internal fluid temperatures 


\section{2 가스켓의 구조 해석}

Fig. 9는 구조해석을 위한 경계조건을 나타내며, 접촉면 $\mathrm{ABC}$ 면은 Frictionless support로 설정하였다. 구조해석의 하중조건(열 전달 해석에서 구한 가스켓 바디 최대온도+유체 최대 압력+볼 트 체결력+플랜지 길이방향 압력)을 Fig. 10에 나타내었다(Shen et al., 2015). 또한 Fig. 8 열전달 해석 결과에서 구한 가스켓 바 디의 최대 온도 분포를 구조해석 하중조건에 적용하였다(Fig. 10 (a)). 볼트 체결력: $33,600 \mathrm{~N}$ (Fig. 10(b)), 내부 유체 최대 압력 $35 \mathrm{MPa}$ (Fig. 10(c)), 플랜지 길이 방향(y방향)으로 발생하는 압력 (pressure 2) -135.04MPa (Fig. 10(d))을 하중조건으로 적용하였다. 가스켓 구조해석 결과 가운데 흑연실에 분포하는 면압 결과 를 Fig. 11에 나타내었다. 그림에서 가스켓 전면 요철부 실부분 의 접촉면압은 $35 \mathrm{MPa}$ 이상으로 균일하며, 또한 후면 요철부 흑 연 실부분의 접촉면압도 $35 \mathrm{MPa}$ 이상 균일하게 발생하고 있는 것을 알 수 있다. 플랜지 내부 유체의 최대 압력 $35 \mathrm{MPa}$ 과 비교 하여 흑연 실부분의 접촉 면압이 크게 발생하고 있는 것을 알 수 있다. 구조해석 결과 상기의 하중조건에서 흑연 실부분의 접

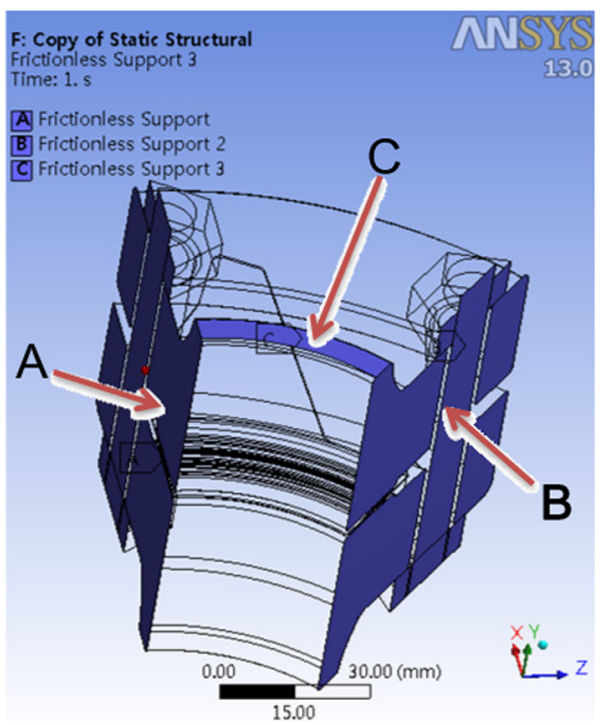

Fig. 9 Boundary conditions for structural analysis

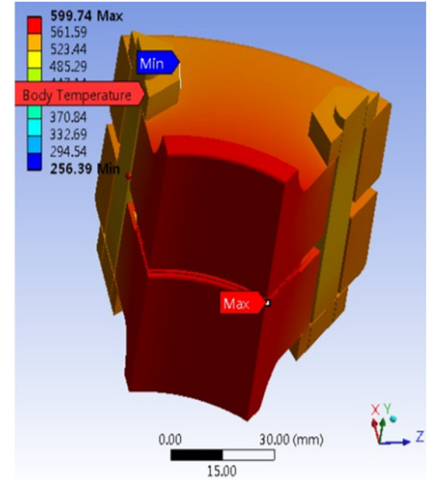

(a)

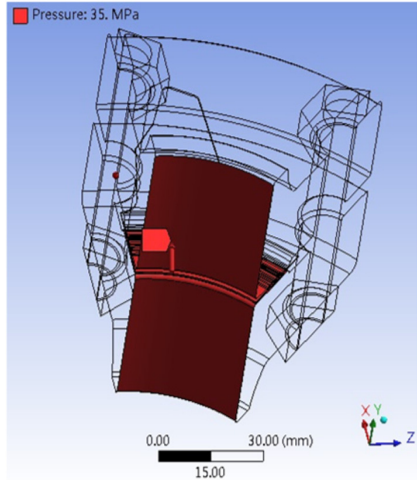

(b)

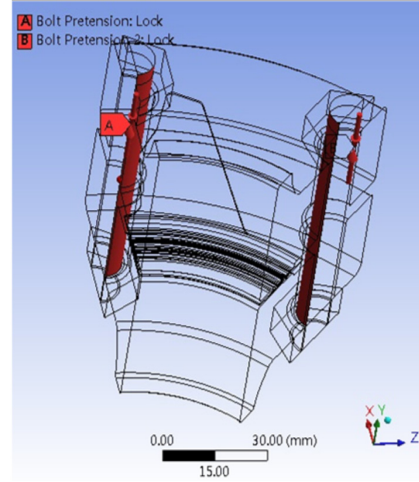

(c)

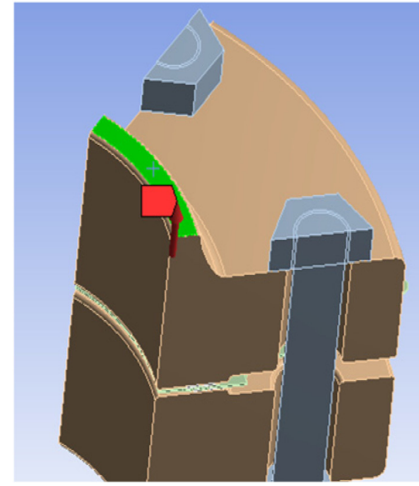

(d)

Fig. 10 Load conditions for structural analysis: (a) Body temperature : $599.74^{\circ} \mathrm{C}$; (b) Pressure 35MPa; (c) Bolt preload : $16800 \mathrm{~N}$; (d) pressure $2-135.04 \mathrm{MPa}$

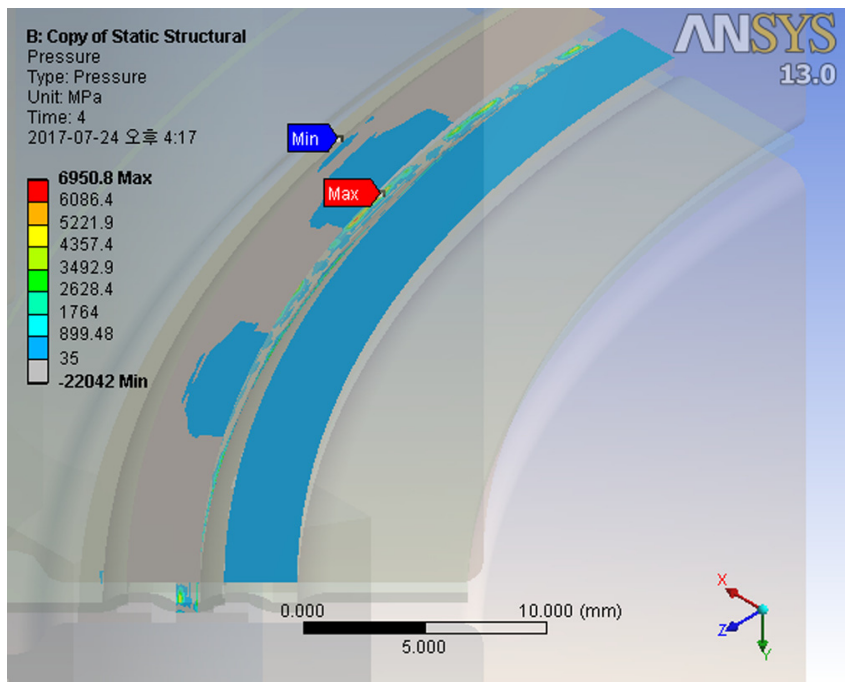

(a)

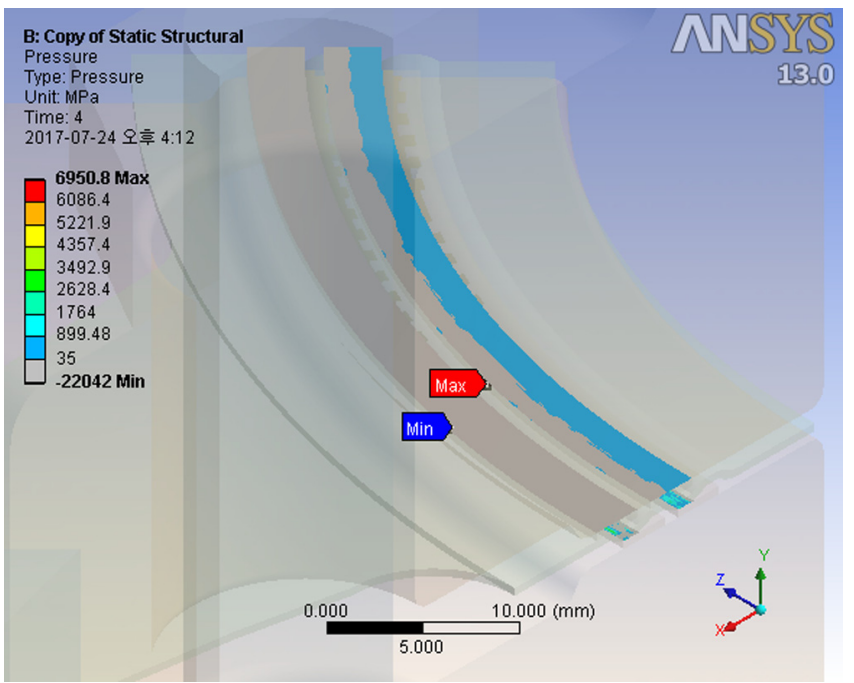

(b)

Fig. 11 Contact pressure at the graphite seal in the semi gasket body: (a) contact pressure of upper side ; (b) contact pressure of bottom side. 
촉면압이 내부 유체 최대압력보다 크기 때문에 플랜지 내부 유 체는 흑연 실부분을 통과하여 누설이 발생하지 않는다고 해석 할 수 있다. 이상의 플랜지용 세미금속 가스켓의 열전달 및 구 조해석 결과를 통하여 플랜지 내부 유체의 최대온도 $600^{\circ} \mathrm{C}$ 및 최대압력 $35 \mathrm{MPa}$ 조건에서 세미 금속 가스켓의 구조 건전성을 검증할 수 있었다.

\section{4. 결 론}

본 연구에서는 흑연실과 결합된 세미금속 가스켓의 구조 건전 성을 평가하기 위하여 플랜지 내부 유체의 최대온도 $600^{\circ} \mathrm{C}$ 및 최 대압력 $35 \mathrm{MPa}$ 조건에서 열전달 및 구조해석을 실시하였다.

(1) 열전달 해석 결과 플랜지 내부 유체온도 $600^{\circ} \mathrm{C}$ 의 경우 가 스켓 바디의 온도 분포는 최대온도 $599.74^{\circ} \mathrm{C}$, 최저온도 $256.39^{\circ} \mathrm{C}$ 를 나타내었다. 내부 유체온도 $22^{\circ} \mathrm{C}$ 와 비교하여 플랜지 내부 유 체온도가 증가할수록 가스켓 바디의 최대온도 및 최저온도의 격차는 크게 나타났다.

(2) 세미금속 가스켓의 구조해석을 위하여 다음의 하중조건 (열전달해석에서 구한 가스켓 바디의 최대온도+유체 최대압력+ 볼트 체결력+플랜지 길이방향 압력)들을 적용하였다. 구조해석 결과 가스켓 요철부 흑연 실부분의 접촉면압이 $35 \mathrm{MPa}$ 이상 균 일하게 발생하였으며, 내부 유체 최대압력 $35 \mathrm{MPa}$ 과 비교하여, 흑연 실부분의 접촉 면압이 $35 \mathrm{MPa}$ 이상 균일하게 발생하고 있 기 때문에 상기의 하중조건에서는 플랜지 내부 유체의 누설이 발생하지 않는다고 해석할 수 있다.

(3) 세미금속 가스켓의 최대 사용조건 유체 온도 $600^{\circ} \mathrm{C}$ 및 압 력 $35 \mathrm{MPa}$ 조건에서 열전달 및 구조해석을 통하여 세미금속 가 스켓의 구조 건전성을 검증할 수 있었다.

(4) 본 연구를 통하여 세미금속 가스켓의 열전달 및 구조해석 방법을 다양한 가스켓에 적용하여 구조 건전성을 해석할 수 있 을 것으로 사료된다.

본 연구의 흑연 실과 결합된 세미금속 가스켓은 고온·고압 환경에서 뛰어난 기밀성능을 발휘하며 또한 기존의 스파이럴 와운드 가스켓과 비교하여 제작비용, 경제성에서 더욱 유리하 여 기존 가스켓을 대체할 수 있다. 특히 선박엔진 배관, $\mathrm{LNG}$ -
LPG선 고압 배관, 해양플랜트 배관 등의 배관 플랜지용 가스켓 으로 크게 활용될 것으로 사료된다.

$$
\text { 후 기 }
$$

본 연구는 2014년도 중소기업기술개발사업 기업부설연구소 신규설치사업(No. C0193754) 지원의 연구결과 중 일부임을 밝 히며, 관계자 여러분께 감사의 말씀을 드립니다.

\section{References}

Afanasov I.M., Savchenko D.V., Ionov S.G., Rusakov D.A., Seleznev A.N., Avdeev V.V., 2009. Thermal conductivity and mechanical properties of expanded graphite, Inorganic Materials, 45(5), 486-490.

Haruyama S., Nurhadiyanto D., Choiron M.A., Kaminishi K., 2013. Influence of surface roughness on leakage of new metal gasket, International Journal of Pressure Vessels and Piping, 111-112, 146-154.

Krishna M.M., Shunmugam M.S., Prasad N.S., 2007. A study on the sealing performance of bolted flange joints with gaskets using finite element analysis, International Journal of Pressure Vessels and Piping, 84, 349-357.

Lee J.C., Park S.H., Lee J.G., Kim P.G., 2013. A Study on simple geometric design method of a high-performance gasket in the refrigerator, The Korean Society of Mechanical Engineers, 212-213.

Mathan G., Prasad N. Siva, 2012. Study of dynamic response of piping system with gasketed flanged joints using finite element analysis, International Journal of Pressure Vessels and Piping, 89, 28-32.

Shen J., Tang Y.F., Liu Y.H., 2015. Buckling analysis of pressure vessel based on finite element method, Procedia Engineering, 130, 355-363. 